Abstracta Iranica Abstracta Iranica

Revue bibliographique pour le domaine irano-aryen

Volume 32-33 | 2013

Comptes rendus des publications de 2009-2010

\title{
Pierre Briant, Michel Chauveau (éds.). Organisation des pouvoirs et contacts culturels dans les pays de l'empire achéménide
}

\section{Rémy Boucharlat}

\section{(2) OpenEdition \\ 1 Journals}

\section{Édition électronique}

URL : http://journals.openedition.org/abstractairanica/40209

DOI : 10.4000/abstractairanica.40209

ISSN : 1961-960X

Éditeur :

CNRS (UMR 7528 Mondes iraniens et indiens), Éditions de l'IFRI

\section{Édition imprimée}

Date de publication : 1 décembre 2013

ISSN : 0240-8910

Référence électronique

Rémy Boucharlat, «Pierre Briant, Michel Chauveau (éds.). Organisation des pouvoirs et contacts culturels dans les pays de l'empire achéménide », Abstracta Iranica [En ligne], Volume 32-33 | 2013, document 42, mis en ligne le 01 juillet 2016, consulté le 26 septembre 2020. URL : http:// journals.openedition.org/abstractairanica/40209; DOI : https://doi.org/10.4000/abstractairanica. 40209

Ce document a été généré automatiquement le 26 septembre 2020.

Tous droits réservés 


\title{
Pierre Briant, Michel Chauveau (éds.). Organisation des pouvoirs et contacts culturels dans les pays de l'empire achéménide
}

\author{
Rémy Boucharlat
}

\section{RÉFÉRENCE}

Pierre Briant, Michel Chauveau (éds.). Organisation des pouvoirs et contacts culturels dans les pays de l'empire achéménide. Paris, 2009, 428 p. (Persika, 14)

1 L'aire géographique privilégiée dans ce volume est l'Égypte, objet de sept des treize articles, les autres étant consacrés à la Babylonie et à Persépolis, les deux derniers à l'Asie Mineure. Les données iconographiques en Égypte et en Asie Mineure et plus encore les données textuelles, égyptiennes, babyloniennes, persépolitaines rendent compte de la cohabitation dans un même empire de populations très diverses par la culture, la langue la religion, les traditions, etc. Cette cohabitation provoque des tensions, parfois des oppositions, mais aussi des échanges fructueux, dont les effets dépasseront souvent la période achéménide. Les situations sont variées, y compris à l'intérieur d'une même région, et elles ne peuvent certainement pas se résumer à une distinction simpliste dominants-dominés. La complexité des relations entre les populations - pas seulement deux, l'une perse l'autre autochtone, en particulier dans les grands centres et en Babylonie - ne fait qu'augmenter avec le traitement d'importants corpus de textes récemment découverts, ou plutôt récemment publiés (textes démotiques et babyloniens en particulier) qui donnent à voir des relations administratives, commerciales ou sociales d'une étonnante diversité.

2 Ces contributions, dont quelques-unes sont analysées plus en détail ici (voir c.r. $n^{\circ} 52$, $63,75,84,95$ et 112), n'abordent le plus souvent qu'un petit aspect de ces relations qui 
ne concernent pas seulement l'élite, mais des populations ordinaires chez elles ou déplacées dans une autre région de l'empire (voir les tablettes concernant les Scythes à Persépolis, et autres ethnonymes dans Henkelman, Stolper, c.r. $n^{\circ} 75$, ou encore des travailleurs égyptiens ou leurs amulettes à Persépolis (M. Wasmuth «Egyptians in Persia »)). La fusion dont rêvera Alexandre était un phénomène en marche avant lui, que celle-ci ait été voulue ou non par les rois achéménides.

\section{AUTEURS}

RÉMY BOUCHARLAT

CNRS, Lyon 